\title{
Feasibility of Spanish-language acquisition for acute medical care providers: novel curriculum for emergency medicine residencies
}

This article was published in the following Dove Press journal:

Advances in Medical Education and Practice

18 February 2016

Number of times this article has been viewed

\section{Kristi H Grall' \\ Ashish R Panchal ${ }^{2}$ \\ Eliud Chuffe ${ }^{3}$ \\ Lisa R Stoneking ${ }^{4}$}

'Department of Emergency Medicine, Regions Hospital, Health Partners Institute, St Paul, MN, ${ }^{2}$ Department of Emergency Medicine, Wexner Medical Center, Ohio State University, Columbus, $\mathrm{OH},{ }^{3}$ Department of Spanish and Portuguese, ${ }^{4}$ Department of Emergency Medicine, University of Arizona, Tucson, AZ, USA

Correspondence: Kristi H Grall Department of Emergency Medicine, Regions Hospital, Health Partners Institute, 640 Jackson Street, St Paul, MN 55I0I, USA Email kristi.j.grall@healthpartners.com
Introduction: Language and cultural barriers are detriments to quality health care. In acute medical settings, these barriers are more pronounced, which can lead to poor patient outcomes.

Materials and methods: We implemented a longitudinal Spanish-language immersion curriculum for emergency medicine (EM) resident physicians. This curriculum includes language and cultural instruction, and is integrated into the weekly EM didactic conference, longitudinal over the entire 3-year residency program. Language proficiency was assessed at baseline and annually on the Interagency Language Roundtable (ILR) scale, via an oral exam conducted by the same trained examiner each time. The objective of the curriculum was improvement of resident language skills to ILR level $1+$ by year 3 . Significance was evaluated through repeatedmeasures analysis of variance.

Results: The curriculum was launched in July 2010 and followed through June 2012 (n=16). After 1 year, 38\% had improved over one ILR level, with 50\% achieving ILR 1+ or above. After year 2, 100\% had improved over one level, with $90 \%$ achieving the objective level of ILR $1+$. Mean ILR improved significantly from baseline, year 1 , and year $2(F=55, d f=1 ; P<0.001)$.

Conclusion: Implementation of a longitudinal, integrated Spanish-immersion curriculum is feasible and improves language skills in EM residents. The curriculum improved EM-resident language proficiency above the goal in just 2 years. Further studies will focus on the effect of language acquisition on patient care in acute settings.

Keywords: language, Spanish, immersion curriculum, emergency medicine, graduate medical education

\section{Introduction}

In 2003, the US Institute of Medicine reported that despite increased awareness, racial and ethnic disparities persisted in health care. ${ }^{1}$ These disparities are particularly dramatic in the Hispanic population, which is the fastest growing population in the US. ${ }^{2}$ Multiple studies have demonstrated that racial disparities occur in treating significant modifiable risk factors for common diseases (ie, hypertension and diabetes) having a significant impact on morbidity and mortality. ${ }^{3-5}$ The rapid rate of growth in this population has lead to a widening language and cultural gap, reinforcing disparate health care. ${ }^{6}$

This is particularly damaging for individuals in need of urgent or emergent medical care. ${ }^{6}$ Influence of the language and cultural gap is evident in patients' dissatisfaction with provider listening skills, answers to questions, explanations of medications, tests, and procedures, and their own ability to receive reassurance and support from care providers. $^{7}$ On discharge from the emergency department (ED), these patients are 
less likely to understand their diagnosis, fill prescriptions, or comply with a follow-up care plan. ${ }^{8,9}$ This manifests as a greater risk of serious adverse outcomes in limited Englishproficiency (LEP) hospitalized patients, as opposed to their English-speaking counterparts, due to communication barriers. ${ }^{10}$

The Centers for Medicare and Medicaid Services requires that all health care providers receiving federal funding must provide trained interpreters in health care settings for LEP patients. ${ }^{11}$ Failure to provide language services can lead to serious medical errors and even liability for malpractice. ${ }^{11}$ Federal law does not mandate whether this service is via a live, contracted interpreter, video interpreting service, or twoway telephone interpreter, but does not permit the interpreter to be a family member. However, in truly emergent situations, these options may not be feasible or immediately available, function poorly due to technical issues, or are not safe due to declining patient clinical status. ${ }^{6}$ This is a significant barrier to care in a situation where timeliness of gathered information can be life-saving.

In this evaluation, we describe the development of a longitudinal, 3-year Spanish-language immersion curriculum for EM residents. To date, there have been little published data regarding the effects of such a curriculum. Our objective was to evaluate the feasibility of the curriculum and the associated improvement in language proficiency. We felt this would help to bridge the language and cultural gap during acute ED presentations to reduce health care disparities in our Hispanic LEP population.

\section{Materials and methods Setting and participants}

A longitudinal Spanish-language immersion curriculum was designed and implemented at the University of Arizona College of Medicine at South Campus (UASC) EM Residency Program. This is an Accreditation Council for Graduate Medical Education (ACGME)-accredited residency-education program located at the UASC. This curriculum was reviewed by and granted exempt status as an educational curriculum by the University of Arizona Institutional Review Board, and in disclosure this study was partially funded by an Academy of Medical Education Scholars/Office of Medical Student Education grant. Study participants included all EM residents who matriculated to the UASC Emergency Medicine Residency Program in July 2010 and July 2011. As this was a curriculum change for the program and not originally intended as a research initiative, no written consent was required from the participants.
The UASC has a large Hispanic/Spanish-speaking population and is located in Tucson, Arizona. The service area encompasses the city of Tucson and Pima County (population $\sim 1$ million). ${ }^{2}$ The majority of Pima County residents are ethnic minorities: 41\% Hispanic and 10\% African American, Native American, or Asian. Fifteen percent of all Tucson residents report being foreign-born (Mexican origin), and an estimated 73,464 Tucson residents are not US citizens. One in four residents speak Spanish at home. ${ }^{2}$

\section{Curriculum description}

The longitudinal Spanish-language immersion curriculum was developed by the Departments of Emergency Medicine and Spanish and Portuguese, University of Arizona. Curriculum development focused on integrating medical Spanish-language and cultural education within the academic core-content criteria for EM as defined by the ACGME. The curriculum was integrated into the weekly EM didactic conference, making participation mandatory.

The key aspects of this curriculum were taught by an associate professor in the Department of Spanish and Portuguese at the University of Arizona. Fundamental features of the program included biweekly didactic modules that included reading, listening, speaking, grammar, writing, and cultural understanding components (Table 1). These modules were "immersion sessions" conducted fully in Spanish as a central facet of the curriculum. The module end points were often achieved through activities that included specific training in obtaining medical history, medications, describing signs and symptoms, and complaint-based patient role-play activities (Table 2). It is important to note that interpreters were still used for clarification and translation services related to medical care.

Specific cultural education was also integrated in the modules. Examples of culturally sensitive topic areas covered included the use of alternative medicine, family ties and their

Table I Key content areas taught in each of the modules of the Spanish-language immersion curriculum

A. Reading activity
B. Listening activity
C. Speaking activity
D. Grammar component
E. Writing component
F. Cultural understanding
G. Medicine in the Spanish world (current and authentic news in Spanish)
H. Important useful phrases
I. Content review using podcast: audio and video
J. Quizzes available online using "Desire to Learn" (D2L) to practice
and review what residents have learned in class
Note: Each module was taught completely in Spanish and held during didactic time.


Table 2 Activities used in modules to teach key content areas in the Spanish-language immersion program

\begin{tabular}{|c|c|}
\hline Greetings & Use of proper greetings in Spanish for all occasions \\
\hline Spanish word of the day & A word that students must master and use during the day \\
\hline Design activities & To help doctors achieve appropriate intended outcomes: (experience, share, process, generalize, and apply) \\
\hline $\begin{array}{l}\text { How to obtain general } \\
\text { information }\end{array}$ & $\begin{array}{l}\text { Como se siente [How are you feeling], tiene dolor [do you have any pain]. Adjectives of comparison: mucho, poco, } \\
\text { nada, [a lot/lots, a little/not much, nothing] }\end{array}$ \\
\hline $\begin{array}{l}\text { Use of Hispanic songs } \\
\text { as a teaching tool }\end{array}$ & “Me arde” [lt burns](Andrés Calamaro), “Mis ojos” (My eyes)(Maná) \\
\hline $\begin{array}{l}\text { Obtaining general } \\
\text { information }\end{array}$ & For example, family illnesses: how to obtain family medical history \\
\hline Medications & Analgésico [analgesic, pain killer], medicina para el dolor [pain killer], etc \\
\hline Body parts & Abdomen [abdomen], ojos irritados [itchy eyes], cabeza [head], brazo [arm], etc \\
\hline Treatment descriptions & Radiografía [an X-ray], tratamiento mediante radiaciones [radiation treatment] \\
\hline Patient habits & $\begin{array}{l}\text { Fumar [to smoke), beber [to drink], corer [to run], comer [to eat], abuso [to abuse, to misuse, to take advantage of], } \\
\text { etc }\end{array}$ \\
\hline $\begin{array}{l}\text { Adjectives to indicate } \\
\text { discomfort and pain }\end{array}$ & $\begin{array}{l}\text { Doloroso(a) [painful] , palpitaciones rápidas [rapid beatings, palpitations]/latidos fuertes del corazón [rapid pulsations of } \\
\text { the heart], reacción [reaction], preparación [to prepare, to be in preparation] }\end{array}$ \\
\hline $\begin{array}{l}\text { Post-treatment useful } \\
\text { vocabulary }\end{array}$ & $\begin{array}{l}\text { Convalecencia [convalescence], etapa de recuperación [time to recuperate, on the road to recovery], recurrente } \\
\text { [recurring] }\end{array}$ \\
\hline $\begin{array}{l}\text { Patient previous } \\
\text { surgeries and implants }\end{array}$ & Marcapasos [cardiac pacemaker], implante [implant], dentaduras [teeth, dentures] \\
\hline Symptoms & $\begin{array}{l}\text { Tener [to have], doler [to hurt, to have pain], molestar [to bother, to annoy, to feel uncomfortable], mareos [dizziness, } \\
\text { giddiness], dolor de pecho [chest pain], dolor de estómago [stomachache], asma [asthma], ETS/enfermedad de } \\
\text { transmisión sexual [STD/sexually transmitted disease], intoxicación por alcohol [alcoholic intoxication], debilidad } \\
\text { [weakness, debility], ataque epileptic [epileptic seizure], etc }\end{array}$ \\
\hline Identifying needs & Physical, social, and emotional needs \\
\hline Memorization & Memorization of useful phrases and vocabulary utilizing iPod, visual aids, etc. \\
\hline $\begin{array}{l}\text { Doctor-patient } \\
\text { sample dialogs }\end{array}$ & To help improve memorization in order to perform the given tasks; students hear, repeat, and respond \\
\hline $\begin{array}{l}\text { Native speaker } \\
\text { demonstrations }\end{array}$ & Authentic/simulation video clips of doctor/patient who performed the tasks \\
\hline Role play & $\begin{array}{l}\text { With selected native speaker demonstrations, residents are given a role and participants will help pinpoint the needs of } \\
\text { the patient based on specific symptoms, etc }\end{array}$ \\
\hline Alternative medicine & Herbal medicines to treat patients, vocabulary to introduce students to alternative medicine \\
\hline
\end{tabular}

Note: Some items appear as Spanish [English translation].

influence on medical care, and dealing with sudden death in the Spanish-speaking community.

\section{Outcome analysis}

Participants were evaluated at baseline, following 1 year of instruction, and at the end of the 2 nd year in a 20 -minute live interview exam. Assessments were standardized and conducted by the same trained oral examiner each time, and included both medical and nonmedical terminology. All language evaluations were scored using the Interagency Language Roundtable (ILR) scale following an Oral Proficiency Interview (OPI) based on the American Council on the Teaching of Foreign Languages guidelines. ${ }^{12-15}$ Descriptions of the ILR level, the OPI descriptor, and the definition of the skill level are included in Table 3. Evaluations were completed by individuals with extensive training in language-ability testing and certification in using the OPI and ILR scales.
The primary outcome measure was resident proficiency in Spanish, confirmed through annual language-competence testing. The target end point was improvement in resident language skills to ILR level $1+$ by year 3 . This end point was defined by whether speakers could initiate and maintain predictable face-to-face conversation and satisfy limited social demands, thus having the ability to communicate directly with their LEP patient should a true emergency arise and an interpreter service not be immediately available. ${ }^{14,15}$

Data were collected and placed in a database and evaluated using Stata 11 (StataCorp LP, College Station, TX, USA). Data are presented as means \pm standard deviation, and comparisons were done using a repeated-measures analysis of variance along with pairwise comparisons.

\section{Results}

The longitudinal Spanish-language immersion curriculum was launched in July 2010 and was followed through 
Table 3 Interagency Language Roundtable (ILR) scale, Oral Proficiency Interview (OPI) descriptor, and their associated skilllevel definitions

\begin{tabular}{|c|c|c|}
\hline ILR scale & OPI descriptor & Definition \\
\hline 5 & Native & $\begin{array}{l}\text { Able to speak like an educated } \\
\text { native speaker }\end{array}$ \\
\hline $4+/ 4$ & Distinguished & $\begin{array}{l}\text { Able to speak with a great deal } \\
\text { of fluency, grammatical accuracy, } \\
\text { precision of vocabulary, and } \\
\text { idiomaticness }\end{array}$ \\
\hline $3+/ 3$ & Superior & $\begin{array}{l}\text { Able to speak the language with } \\
\text { sufficient structural accuracy and } \\
\text { vocabulary to participate effectively } \\
\text { in most formal and informal } \\
\text { conversations }\end{array}$ \\
\hline $2+$ & Advanced Plus & $\begin{array}{l}\text { Able to satisfy most work } \\
\text { requirements and show some ability } \\
\text { to communicate on concrete topics }\end{array}$ \\
\hline 2 & Advanced & $\begin{array}{l}\text { Able to satisfy routine social demands } \\
\text { and limited work requirements }\end{array}$ \\
\hline $\mathrm{I}+$ & Intermediate - High & $\begin{array}{l}\text { Able to satisfy most survival needs } \\
\text { and limited social demands }\end{array}$ \\
\hline \multirow[t]{2}{*}{ I } & Intermediate - Mid & $\begin{array}{l}\text { Able to satisfy some survival needs } \\
\text { and some limited social demands }\end{array}$ \\
\hline & Intermediate - Low & $\begin{array}{l}\text { Able to satisfy basic survival needs } \\
\text { and minimum courtesy requirements }\end{array}$ \\
\hline $0+$ & Novice - High & $\begin{array}{l}\text { Able to satisfy immediate needs } \\
\text { with learned utterances }\end{array}$ \\
\hline \multirow[t]{3}{*}{0} & Novice - Mid & $\begin{array}{l}\text { Able to operate in only a very limited } \\
\text { capacity }\end{array}$ \\
\hline & Novice - Low & $\begin{array}{l}\text { Unable to function in the spoken } \\
\text { language }\end{array}$ \\
\hline & 0 & No ability whatsoever in the language \\
\hline
\end{tabular}

June 2012. Ten residents entered our EM program in July 2010. Six more started a year later, in July 2011, for a total of 16 residents enrolled in this initial Spanish curriculum. The resident data of language proficiency at baseline and following year 1 and year 2 are noted in Table 4 . Baseline testing placed residents in a range on the ILR scale from 0 - to $3+$. After 1 year of participation, 38\% (six of 16) residents raised their proficiency by greater than one ILR level. Of these residents, $50 \%$ (eight of 16) had already attained the final benchmark ILR level $1+$ or above. After only 2 years of participation, $100 \%$ (ten of ten) of the original ten residents had increased their language proficiency by one level on the ILR scale, and $90 \%$ (nine of ten) of these reached ILR level 1+. One participant did not reach ILR level 1+, but was able to raise one ILR level, starting at $0-$ and ending at $1-$ (Table 4).

An analysis of variance for repeated measures was conducted for the three time points (baseline, year 1, and year 2), indicating a significant improvement in their language proficiency over time $(F=55, d f=1 ; P<0.001)$. In pairwise
Table 4 Resident language-acquisition testing on the ACTFL/OPI scale at baseline, following I year and 2 years in the program

\begin{tabular}{llll}
\hline $\begin{array}{l}\text { Resident } \\
\text { number }\end{array}$ & Baseline & $\begin{array}{l}\text { Following } \\
\text { year I }\end{array}$ & $\begin{array}{l}\text { Following } \\
\text { year 2 }\end{array}$ \\
\hline 1 & $1+$ & 2 & $2+$ \\
2 & $1+$ & $2-$ & $2+$ \\
3 & $2-$ & $2+$ & 4 \\
4 & $2+$ & $3+$ & - \\
5 & $0-$ & $1+$ & - \\
6 & $0+$ & 3 & - \\
7 & $0-$ & $0-$ & - \\
8 & $0-$ & $0-$ & - \\
9 & $0+$ & $2+$ & - \\
10 & $0-$ & $1-$ & $1+$ \\
11 & $0-$ & $0+$ & 2 \\
12 & $0-$ & $0-$ & $1-$ \\
13 & $3+$ & $4-$ & $4+$ \\
14 & $0+$ & $0+$ & $1+$ \\
15 & $0-$ & $0+$ & $1+$ \\
16 & $0-$ & 1 & $2+$ \\
\hline
\end{tabular}

Note: Residents with just "-" were junior residents who had not completed their 2nd year of training.

Abbreviations: ACTFL, American Council on the Teaching of Foreign Languages; OPI, Oral Proficiency Interview.

comparisons, there was a significant improvement from baseline to the end of year 1 and end of year $2(P<0.05)$. Data collection was evaluated at this point because of unanticipated success in language acquisition after only 2 years.

\section{Discussion}

Health care disparities from a widening language and cultural gap in our population are a significant problem in medicine, even when controlling for social and economic variables. ${ }^{16}$ Innovative solution approaches may be necessary. One such possibility is improving provider language skills. In the ED, due to high patient acuity and true emergencies, there can occasionally be limited time to wait for interpreters, and providers equipped with language skills who can initiate history taking in Spanish until an interpreter is available may be essential. Previous work has demonstrated that short interventions with limited language acquisition may have profound effects on patient perception of care, ${ }^{17}$ yet can be the cause of errors when learners rely on their own developing skills rather than use the skills of a trained interpreter. ${ }^{18}$ However, it is unclear to what extent a longitudinal, immersive course would improve providers' language abilities or quality of patient care.

As per a recent Institute of Medicine report on emergency care, ethnic and racial disparities persist in both the ED and hospital setting despite providers' best intentions. ${ }^{19}$ In EM, a number of studies have noted these effects with respect to the 
amount of analgesia given, ${ }^{20}$ higher rates of missed cardiac ischemia, ${ }^{21}$ lower rates of cardiac catheterization, ${ }^{22}$ and lowerquality care for congestive heart failure and pneumonia. ${ }^{23}$ Racial disparities have been linked to many medical conditions, including coronary artery disease, cancer, HIV, diabetes, and trauma. ${ }^{24}$ While it is unclear exactly what role language plays in these disparities, these disease processes commonly present in the ED in acutely decompensated states, requiring immediate critical care management.

In this evaluation, we describe a longitudinal Spanishlanguage immersion curriculum that demonstrated improved language acquisition for EM residents. This curriculum improved residents' language proficiency, with $100 \%$ (ten of ten) of residents improving their language proficiency by one level on the ILR scale. Further, 90\% (nine of ten) of these residents reached the 3 -year goal ILR level of $1+$ after only 2 years of participation. Although our sample size was arguably limited, this investigation demonstrates that improved physician language acquisition is feasible through an integrated longitudinal immersion program as part of residency training.

Traditionally, residency education is directed solely at the ACGME core competences, which do not specifically include a language-acquisition requirement. However, the ACGME does have core competences for interpersonal and communication skills and professionalism, which include a broader sense of cultural competence. This program fulfills these requirements through striving to reduce health care disparities for the Hispanic population. Other residency programs have also offered language training to their providers. A pediatric EM program provided residents with a 10 -week course in medical Spanish. ${ }^{17}$ After language acquisition, patient families felt the resident physician was more concerned about their child, made them feel comfortable, was respectful, and listened to their concerns. ${ }^{17}$ Further, it improved patients' and families' satisfaction with the medical provider. ${ }^{17}$ Because of this, a number of institutions have successfully implemented curricula in language acquisition and cultural competency. ${ }^{25,26}$ For the most part, these courses are short-term, not longitudinal, and not immersive. This curriculum is the first program, to our knowledge, to incorporate both a longitudinal and immersive aspect in the training of language acquisition with cultural competence into graduate medical education.

Future goals are to assess the extent to which this program is bridging the language and cultural gap that is inherent in our ED environment, and ultimately demonstrate improved patient care (LEP patient satisfaction with our providers, as well as reduction in medical error attributable to language discordance). We also aim to provide dual-role provider certification to participants who demonstrate readiness on assessment testing.

This program was integrated into our current resident didactic curriculum, and does not take the place of any of the key core content. However, one practical consideration is that residents provide daily medical care to an exceptionally high population of LEP and native Spanish speakers in the ED. This might have assisted in the program's success due to the frequent use of newly acquired skills, and limits eventual portability to other environments with a less dense population of LEP patients.

While a control group of residents who did not participate in the curriculum would have added further credence to the success of our program, we felt an obligation to provide language immersion to all of our resident providers who care for our LEP patients. In the future, we plan to compare the language performance of our residents to those at another site who are not enrolled in a language-acquisition program.

\section{Conclusion}

In this study, we demonstrated that the implementation of a longitudinal Spanish-immersion curriculum improved language skills in EM residents. The program improved the language proficiency of our residents while educating them on the culturally sensitive needs of their patients. The final goal of the program was level $1+$ on the ILR scale, and we found that $90 \%$ of our residents were able to achieve this level after only 2 years of participation.

\section{Disclosure}

The authors report no conflicts of interest in this work.

\section{References}

1. Institute of Medicine of the National Academies. Unequal Treatment: Confronting Racial and Ethnic Disparities in Health Care. Washington: National Academies Press; 2003.

2. United States Census Bureau. Statistical Abstract of the United States 2012: The National Data Book. 131st ed. (library edition). Lanham, MD: Bernan Press; 2011

3. Gonzalez AB, Salas D, Umpierrez GE. Special considerations on the management of Latino patients with type 2 diabetes mellitus. Curr Med Res Opin. 2011;27(5):969-979.

4. Guzman NJ. Epidemiology and management of hypertension in the Hispanic population: a review of the available literature. Am J Cardiovasc Drugs. 2012;12(3):165-178.

5. Danaei G, Rimm EB, Oza S, Kulkarni SC, Murray CJ, Ezzati M. The promise of prevention: the effects of four preventable risk factors on national life expectancy and life expectancy disparities by race and county in the United States. PLoS Med. 2010;7(3):e1000248.

6. Riera A, Walker DM. The impact of race and ethnicity on care in the pediatric emergency department. Curr Opin Pediatr. 2010; 22(3):284-289.

7. Morales L, Cunningham W, Brown J, Lui H, Hays R. Are Latinos less satisfied with communication by health care providers? J Gen Intern Med. 1999;14(7):409-417. 
8. Carrasquillo O, Orav J, Brennan T, Burstin H. Impact of language barriers on patient satisfaction in an emergency department. $J$ Gen Intern Med. 1999;14(2):82-87.

9. Hornberger J, Itakura H, Wilson S. Bridging language and cultural barriers between physicians and patients. Public Health Rep. 1997;112(5): 410-417.

10. Cohen A, Rivara F, Marcuse E, McPhillips H, Davis R. Are language barriers associated with serious medical events in hospitalized pediatric patients? Pediatrics. 2005;116(3):575-579.

11. Centers for Medicare and Medicaid Services. Strategic Language Access Plan (LAP) to Improve Access to CMS Federally Conducted Activities by Persons With Limited English Proficiency (LEP). Baltimore: Department of Health and Human Services: 2014. Available from: https://www. cms.gov/About-CMS/Agency-Information/OEOCRInfo/Downloads/ CMS-LAP-Updated-2014-508.pdf. Accessed November 23, 2015.

12. American Council on the Teaching of Foreign Languages. ACTFL Proficiency Guidelines 2012. Alexandria (VA): ACTFL; 2012. Available from: http://www.actfl.org/sites/default/files/pdfs/public/ACTFLProficiency Guidelines2012_FINAL.pdf. Accessed November 23, 2015.

13. Clark JL, Clifford RT. The FSI/ACTFL proficiency scales and testing techniques. Stud Second Lang Acquis. 1988;10(2):129-147.

14. Interagency Language Roundtable [website on the Internet]. Available from: http://www.govtilr.org/index.htm. Accessed November 25, 2014.

15. SIL International. Correspondence of proficiency scales. 1999. Available from: http://www-01.sil.org/lingualinks/languagelearning/ MangngYrLnggLrnngPrgrm/CorrespondenceOfProficiencySca.htm. Accessed November 23, 2015.

16. Bostick N, Morin K, Benjamin R, Higginson D. Physicians ethical responsibilities in addressing racial and ethnic healthcare disparities. J Natl Med Assoc. 2006;98(8):1329-1334.
17. Mazor S, Hampers L, Chande V, Krug S. Teaching Spanish to pediatric emergency physicians: effects on patient satisfaction. Arch Pediatr Adolesc Med. 2002;156(7):693-695.

18. Prince D, Nelson M. Teaching Spanish to emergency medicine residents. Acad Emerg Med. 1995;2(1):32-36.

19. Institute of Medicine. The future of emergency care in the United States health system. 2012. Available from: https://iom.nationalacademies. org/Activities/Quality/emergencycare.aspx. Accessed November 23, 2015.

20. Todd KH, Deaton C, D'Adamo AP, Goe L. Ethnicity and analgesic practice. Ann Emerg Med. 2000;35(1):11-16.

21. Pope JH, Aufderheide TP, Ruthazer R, et al. Missed diagnoses of acute cardiac ischemia in the emergency department. $N$ Engl J Med. 2000; 342(16):1163-1170.

22. Chen J, Rathore SS, Radford MJ, Wang Y, Krumholz HM. Racial differences in the use of cardiac catheterization after acute myocardial infarction. N Engl J Med. 2001;344(19):1443-1449.

23. Ayanian JZ, Weissman JS, Chasan-Taber S, Epstein AM. Quality of care by race and gender for congestive heart failure and pneumonia. Med Care. 1999;37(12):1260-1269.

24. Wong MD, Shapiro MF, Boscardin WJ, Ettner SL. Contribution of major diseases to disparities in mortality. $N$ Engl J Med. 2002; 347(20):1585-1592.

25. Bereknyei S, Nevins A, Schillinger E, et al. Beyond knowledge, toward linguistic competency: an experiential curriculum. J Gen Intern Med. 2010;25 Supp1 2:S155-1S59.

26. Rosen J, Spatz ES, Gaaserud AM, et al. A new approach to developing cross-cultural communication skills. Med Teach. 2004; 26(2):126-132.
Advances in Medical Education and Practice

\section{Publish your work in this journal}

Advances in Medical Education and Practice is an international, peerreviewed, open access journal that aims to present and publish research on Medical Education covering medical, dental, nursing and allied health care professional education. The journal covers undergraduate education, postgraduate training and continuing medical education

\section{Dovepress}

including emerging trends and innovative models linking education, research, and health care services. The manuscript management system is completely online and includes a very quick and fair peer-review system. Visit http://www.dovepress.com/testimonials.php to read real quotes from published authors. 